
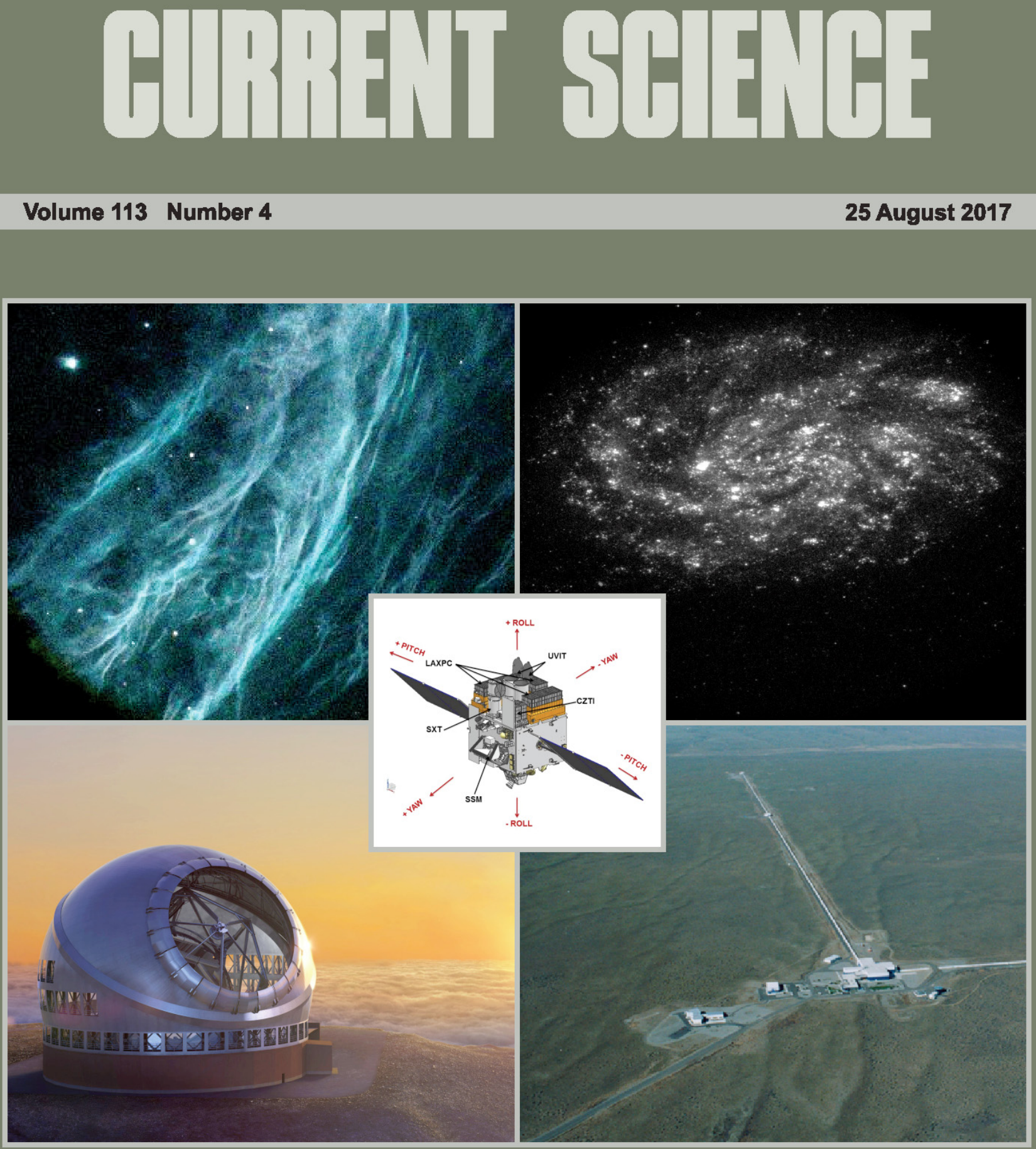

Special section: Astronomy

Media coverage of wildlife

Pharmaceutical patenting trends 


\title{
Pharmaceutical patenting trends on drugs and lifestyle diseases: an analysis of Indian and global status
}

\author{
Vikram Singh $^{1, *}$, Kajal Chakraborty ${ }^{2}$ and Lavina Vincent ${ }^{2}$ \\ ${ }^{1}$ Intellectual Property and Technology Management Unit, Indian Council of Agricultural Research, New Delhi 110012 , India \\ ${ }^{2}$ Institute Technology Management Unit, Central Marine Fisheries Research Institute, Ernakulam North PO, P. B. No. 1603, Cochin 682 018, India
}

\begin{abstract}
The Indian pharmaceutical sector is large and has the potential of a global leader for low-priced high-quality drugs. The new patent regulations had a strong impact on the drug industry in India. There is a serious decline in the number of pharma patents recently after compulsory licensing for drugs was implemented in India. While regulations are meant for reducing the prices of essential drugs, there are investment-related issues when a patent is subjected to voluntary licensing. The present study focuses on three phases in pharmaceutical patenting identified by analysing the major patent databases and the potential shift in pharma patenting sector from acute to lifestyle disease-based drugs. The recent trend identified in the pharma patenting sector in India is quite unusual and unreported so far.
\end{abstract}

Keywords: Compulsory licensing, generic drug market, Indian pharma market, lifestyle diseases, pharma patenting trends.

THE past two decades have revolutionized patenting and licensing in the Indian pharmaceutical sector. There has been a drastic development in this field due to high demand for generic drugs in developed countries, patent expiry and the growing importance of biologics. In 2015, the Indian pharma market was dominated by generic drugs $(71 \%)$ followed by over-the-counter (OTC) medicines $(19 \%)$ and patented drugs $(10 \%)$. Demand for patented branded drugs has declined due to growing importance of generic drugs. In 2010, the share of patented drugs was $70 \%$ in the global market, which declined to $53 \%$ in 2015 (ref. 1). Between 2006 and 2015, a total of 67,342 patents were granted in India, of which 56,727 were foreign and 10,615 were Indian inventors. There has been a gradual decrease in patents filed in the Indian patent office during the past 5 years ${ }^{2}$. According to the World Intellectual Property Organization (WIPO) Global Innovation Index-2015, of the 141 economies surveyed in the world, India ranked 81 st in position ${ }^{3}$. Indian companies are among world leaders in the production of generics and vaccines. India accounted for $20 \%$ of the global generic market by volume in 2010 , which increased to $22 \%$

*For correspondence. (e-mail: kmnmvs@gmail.com) in 2015. Of late, generic manufacturers are facing problems in manufacture and supply of generic versions of new patented medicines resulting in an increase in the dependency of imported expensive medicines, which has disturbed the Indian pharma generic market ${ }^{4}$.

The present study analyses pharma patenting in India for the past two decades and classifies the sector into three phases. The increase in sale of drugs for lifestyle diseases has boosted the Indian pharmaceutical sector. The drug trends for 5 major lifestyle diseases during 2010-2015 are also analysed.

\section{Data source and methodology}

The primary information for analysis of patenting trends with respect to pharmaceuticals in India was compiled from Indian Patent Advanced Search System (InPASS) patent search using the search option - Field of invention: (FI11) Pharmaceuticals. Information on generic drugs, biologics/biopharma drugs, marine drugs, biosimilars and lifestyle diseases was obtained from Espacenet database. The secondary information was collected from various printable and non-printable sources, such as search engines, news and government websites, online journals, white papers, magazines, company reports, books and other accessible databases. Data available on top International Patent Classification (IPC) codes, top assignees, legal status and the patents reported in different technology domains in pharma patenting were analysed using Questel - 'Orbit' software. Technology domains for nonsteroidal anti-inflammatory drugs (NSAIDs), anti-cancer drugs and anti-diabetes drugs related patents were also examined. The software provides a comprehensive suite of tools to analyse individual databases, make database clusters and merge them into a single database.

\section{Results and discussion}

\section{Indian scenario - pharmaceutical patenting activity trend}

The regulations governing pharma patenting sector in India enable citizens to access medicines at cheaper prices. 

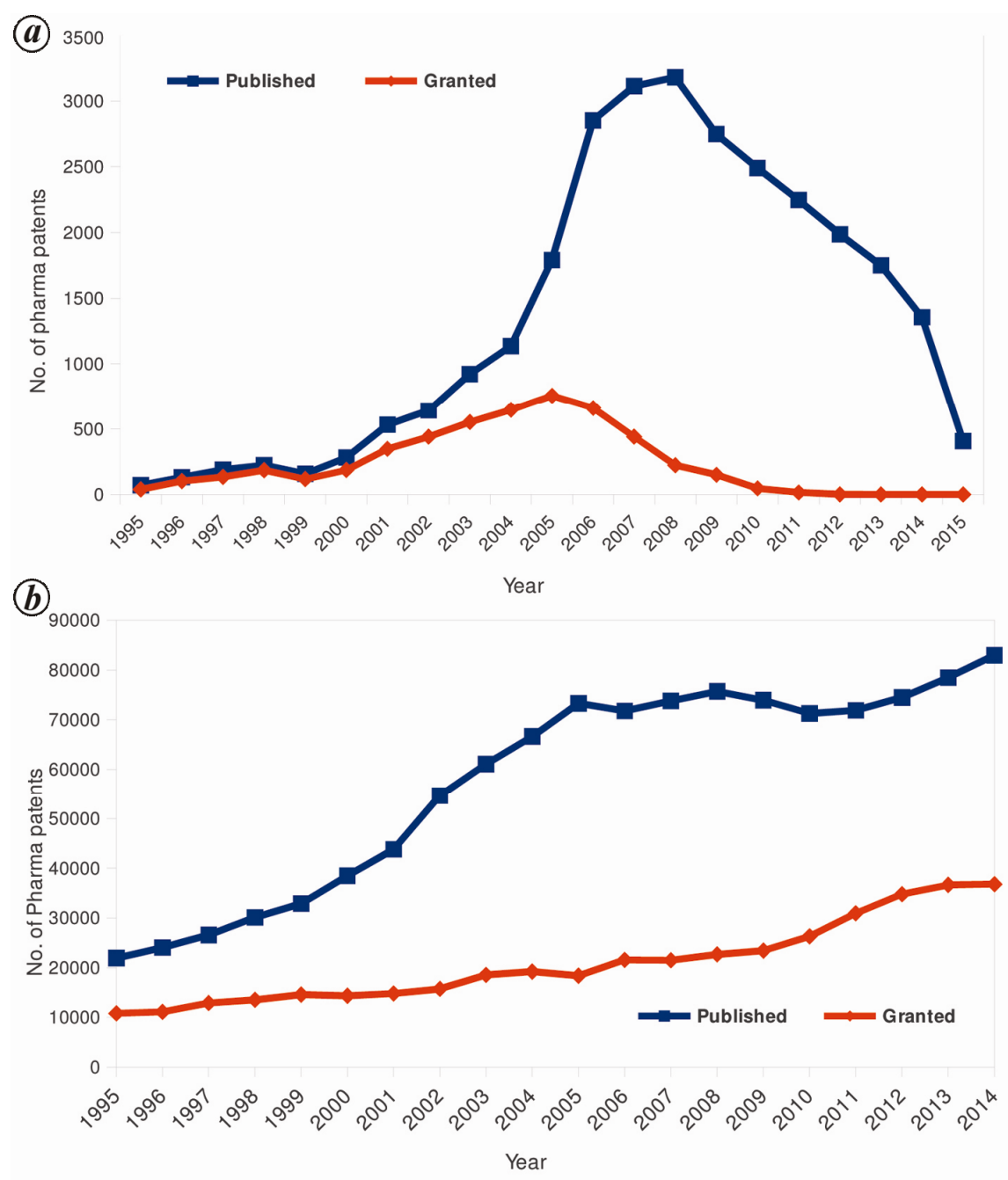

Figure 1. $\boldsymbol{a}$, Indian pharma patenting trend (Source: InPASS data). $\boldsymbol{b}$, Global pharma patenting trend (Source: Espacenet Data).

The Indian patent system underwent different amendments to realize this aim and the government took strong measures, such as compulsory licensing, enabling the Indian pharma patenting. The Indian Patent Act was formulated in 1970, which allowed process patent protection for chemicals and pharmaceutical products for a short span of 7 years. Prior to this act, the global multinational manufacturers controlled the Indian pharmaceuticals market. The process patent act encouraged the Indian domestic market to manufacture essential drugs leading to a boom in the production of generic drugs. Till date, India is the largest provider of generic drugs globally. In the past two decades, the pharma patenting regime in India has undergone a parabolic shift (Figure $1 a$ ) based on which it has been classified into three phases.

\section{Phase I (1995-2005)}

Generic drugs prevailed in the Indian pharmaceutical market. This was in tune with the process patent domain initiated since the Indian Patent Act 1970. The research and development (R\&D) fund allocation decreased during this phase as the domestic pharmaceutical companies did not invest in R\&D to develop new and innovative therapeutic drugs. The focus of the Indian pharmaceutical companies during this phase was to manufacture generic versions of patented drugs. As a result, India became a source of cheap generic drugs for supply to the third world and other developing countries. The Indian healthcare system immensely benefited during this phase with cheaper generic drugs when compared to similar versions in the global market.

\section{Phase II (2006-2010)}

The Indian government introduced product patents under the Patents (Amendment) Act, 2005 to spur more R\&D activities in India and to encourage both domestic and multinational firms. The product patents facilitated the global pharma companies to bring their patented products 
to India, which led to the transfer of technologies in the pharmaceutical sector from developed nations. More pharma patenting was reported during this period in India (Figure $1 a$ ). Globally more investments were made in R\&D activities during this phase, opening new areas of research, such as biotechnology, bioinformatics, biopharmaceuticals, etc. Drugs from natural biological sources were attaining relevance, which led to the emergence of biologics and biosimilars. Domestic companies were unable to invest heavily in $\mathrm{R} \& \mathrm{D}$ of new innovative drugs. Subsequently, Indian companies started licensing arrangements, such as out-licensing of molecules or in-licensing of competent molecules with multinational companies to develop novel drugs. In the meantime, generic drug companies, which dominated the domestic market started to export generic versions of off-patent drugs. Towards the end of this phase, it was observed that generic drugs continued to rule the domestic pharma market accounting for $20 \%$ of the global generic market; there was an increase in the number of pharma patents published and the evolution of biologics and biosimilars in India.

\section{Phase III (2011-2015)}

This is a new phase observed in the pharma patenting sector of India. The increase in number of pharma patents in the second phase led to an increase in the price of pharmaceutical drugs. There was a hue and cry for regulating the prices of critical drugs, such as anti-cancer drugs in India leading to internal issues in the Indian health care system. After a few deliberations, it was decided to regulate the drug prices by compulsory licensing of few drugs; for example in 2012, India issued a compulsory license for Bayer's cancer drug Nexavar to Natco Pharma to produce a generic version of Nexavar, citing concerns that the drug was not accessible to patients in the country ${ }^{5}$. Compulsory licensing is a license issued by the state authority to a company violating the rights of the patent holder. This became a debated issue in the drug patenting circle at an international level. Many companies, who had the patented products in India, raised severe objections to compulsory licensing. There are reports on the onset of compulsory licences for three more anti-cancer patented drugs, i.e. dasatinib, ixabepilone and trastuzumab. The uprising of compulsory licensing set an impulse for voluntary licensing in the Indian pharma market. The voluntary licensing agreement between the original drug maker and a local or retail drug producer is an exclusive manufacturing and marketing alliance ${ }^{6}$. The pharmaceutical companies are adopting this as a business strategy, which has recently raised concerns in the Indian pharma market. For example, a voluntary license agreement was signed between 11 Indian generic drug producers and Gilead Science to bring the blockbuster Hepatitis
C drug Sovaldi to Indian markets. Although 49 million Hepatitis $\mathrm{C}$ patients live in middle-income countries, the voluntary license prevents export of the generic drug to middle-income countries. This may curb the growth of Indian generic market. "The Indian government has expressed concern that India will no more be the 'pharmacy of the world' if generic companies 'gave up' the fight for access to affordable drugs' ${ }^{4}$. There was a decrease in pharma patenting trends towards the end of this phase (Figure $1 a$ ). Issuing compulsory license for international drugs could be a reason. The number of granted pharma patents during 2013-2015 was nil; the reason could be less number of patent examiners compared to the rise in number of pharma patents filed. Though there are concerns with respect to the growth of the generic market in future, the generic drugs continue to dominate the Indian pharma market.

\section{Global scenario of pharmaceutical patenting}

The data on pharmaceutical patenting globally for the last two decades was obtained from Espacenet database. There was an increase in pharmaceutical patenting trend at the global level when compared to India (Figure $1 b$ ). During the first phase (1995-2005), there was a gradual increase till 2000; subsequently, there was an exponential increase in patenting trend till 2005. During 2006-2010 (second phase) the pharma patenting trend was found to be almost stationary at global level. The third phase (2011-2015) indicates a surge in global pharma patenting trend.

Apart from branded patented drugs, the other categories of drugs in pharmaceutical market were biopharma/biologics, generic, biosimilar and marine drugs. The data for patents filed during the past 20 years for the process or products related to these drugs were taken from Espacenet. From the data (Figure $2 a$ ), it could be inferred that other than branded patented drugs, the number of patents related to generic drugs was high compared to other categories of drugs. Patenting in biopharmaceuticals emerged in 2002, which has gained importance and continued to grow till 2015. Over the past two decades, limited patenting activity has been reported related to marine pharma drugs and biosimilars.

\section{Lifestyle diseases}

In the Indian pharmaceutical sector, drugs for acute diseases dominated, but recently, with increasing urbanization and modern style of living, about $50 \%$ of expenditure related to pharmaceutical drugs is for lifestyle diseases. The World Health Organization (WHO) survey states that about $60 \%$ of the total mortality reported annually in India is due to lifestyle-related diseases, such as cardiovascular diseases $26 \%$, diabetes $2 \%$, respiratory diseases 

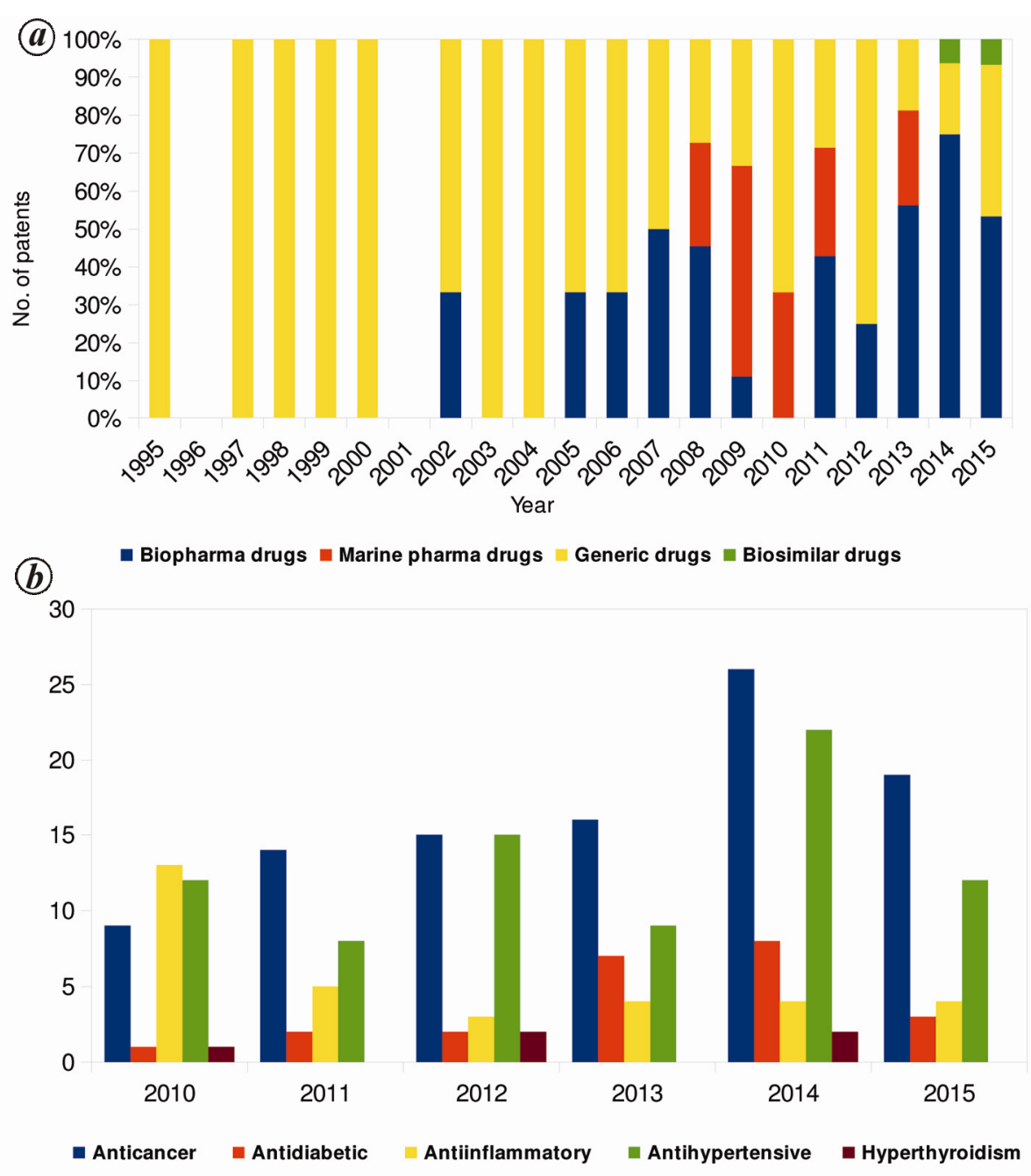

Figure 2. a, Global pharma patenting in different categories of drugs (Source: Espacenet data). $\boldsymbol{b}$, Patenting trends for five major lifestyle diseases (Source: Espacenet data).

$13 \%$, cancer $7 \%$, others $12 \%$ (ref. 7 ). Patel et al. ${ }^{8}$ forecasted that around $75 \%$ of all deaths in India will be due to chronic lifestyle diseases in 2030. Cancer fatalities will rise to 1.5 million, cardiovascular deaths to 4 million, and coronary heart disease deaths to 17.9 million in 2030 (ref. 9). The surge in lifestyle diseases in India has boosted the sale of drugs for chronic diseases such as diabetics, oncology, cardiovascular, etc. Apart from chemical formulation of drugs, marine nutraceuticals and drugs have also contributed towards the cure of different lifestyle diseases. The pharma patenting trends for drugs on five major lifestyle diseases, i.e. cancer, diabetes, inflammatory, hypertensive and hyperthyroidism drugs, in the past five years were analysed from the data obtained from Espacenet (Figure $2 b$ ).

\section{Anticancer drugs}

The global anti-cancer drug market had reached 100 billion USD in 2014 and could reach 147 billion USD by
2018 (ref. 10). Global players such as Roche, Novartis, Pfizer and others dominated the oncology drug market. The major companies in India producing anti-cancer drugs are Cipla limited, Sun Pharma and Dr Reddy Laboratories. With growing awareness on treatment of cancer, there has been a greater influx in anti-cancer drugs $s^{11}$. Recently, the major global companies in oncology have started to pursue potential combination therapies for cancer. Over the past five years, the highest number of patents relating to anti-cancer drugs were filed in 2014 (Figure $2 b$ ). The oncology drug market gained more attention at the international level when compared to other lifestyle diseases in the current study.

\section{Anti-diabetic drugs}

Based on rapid growth in diabetes incidences globally, the International Diabetes Federation forecasted an increase up to 552 million USD by 2030 (ref. 12). The global spending on diabetes has increased by $47 \%$ during 
the past five years $(2010-2015)^{11}$. During this period, anti-diabetes drugs topped pharma sales in India. In 2015, the anti-diabetes drugs grew at $32.9 \%$ by value among different segments of the Indian pharmaceutical market ${ }^{13}$. The most prescribed anti-diabetes drug is a combination of glimepiride and metformin, marketed as Glycomet GP and Gluconorm-G (ref. 14). The domestic market of antidiabetes drug is ruled by major foreign companies, such as Novo Nordisk, Eli Lily and GlaxoSmithKline. The increase in urbanization and health insurance policies for diabetes has boosted the anti-diabetes drug market in India. The R\&D activities for novel anti-diabetes drugs have led to the emergence of biologics in this arena. Various biopharmaceutical drugs for diabetes are undergoing clinical trials. Lately, in 2015, a marine nutraceutical 'Cadalmin ${ }^{\mathrm{TM}}$ ADe' from seaweeds was patented in India, which has active ingredients to act against type-II diabetes ${ }^{15}$. At the global level the anti-diabetes drugs related patenting trends were high in 2013 and 2014 according to data obtained from Espacenet (Figure $2 b$ ).

\section{Anti-inflammatory drugs}

The global anti-inflammatory therapeutics market is expected to grow at a rate of $5.9 \%$ from 2014 to 2020 . Antiinflammatory biologics are more effective and have lesser side effects when compared to the conventional drugs. Anti-inflammatory drugs include drugs for arthritis, respiratory diseases, multiple sclerosis, psoriasis, inflammatory bowel disease, etc. Anti-inflammatory biologics are the most preferred drugs for the treatment of arthritis. It accounts for $54.8 \%$ share of the global anti-inflammatory therapeutics market ${ }^{16}$. India had lately filed a patent for a product 'Cadalmin ${ }^{\mathrm{TM}}$ GMe', a marine anti-inflammatory biologic having bioactive ingredients extracted from green mussel Perna viridis to combat inflammatory diseases, such as arthritis, joint pain, etc. Marine nutraceuticals, such as 'Cadalmin ${ }^{\mathrm{TM}} \mathrm{GAe}$ ' from seaweeds or marine macroalgae (seaweeds) also contain ingredients to treat inflammatory pain and arthritis ${ }^{17}$. There has been a decline in the patenting trends related to anti-inflammatory drugs during the past five years (Figure $2 b$ ). The highest number of patents filed were in 2010 followed by a rapid decrease during 2011-2015. There are initiatives, such as 'drugs from the sea' campaign for utilizing the bio-active properties from resources of marine origin, which can replace costlier terrestrial counterparts in bio-similar drugs.

\section{Anti-hypertensive drugs}

At the global level, the pharma market analysts had forecasted that antihypertensive drug market will grow at a compound annual growth rate (CAGR) of $1.2 \%$ from 2013 to 2018 (ref. 18). Some of the major antihypertensive drug patents such as Diovan expired, which led to a decline in the growth of the antihypertensive market. The current status of anti-hypertensive drug under the cardiovascular segment represents $13 \%$ of the Indian pharma market ${ }^{13}$. Lately, with the prevalence of lifestyle diseases, the cardiovascular segment is the third major sector in the Indian pharma market that has gained attention for R\&D activities. Despite fluctuations in the patenting trends of anti-hypertensive drugs over the past five years, its contribution is likely to rise due to increase in the number of patients suffering from hypertension. During 2010-2015, the highest number of patents related to anti-hypertensive drugs was filed (Figure $2 b$ ).

\section{Hyperthyroidism drugs}

The occurrence of thyroid disorders differs according to geographical distribution, diet, nutrition and population.

(a)
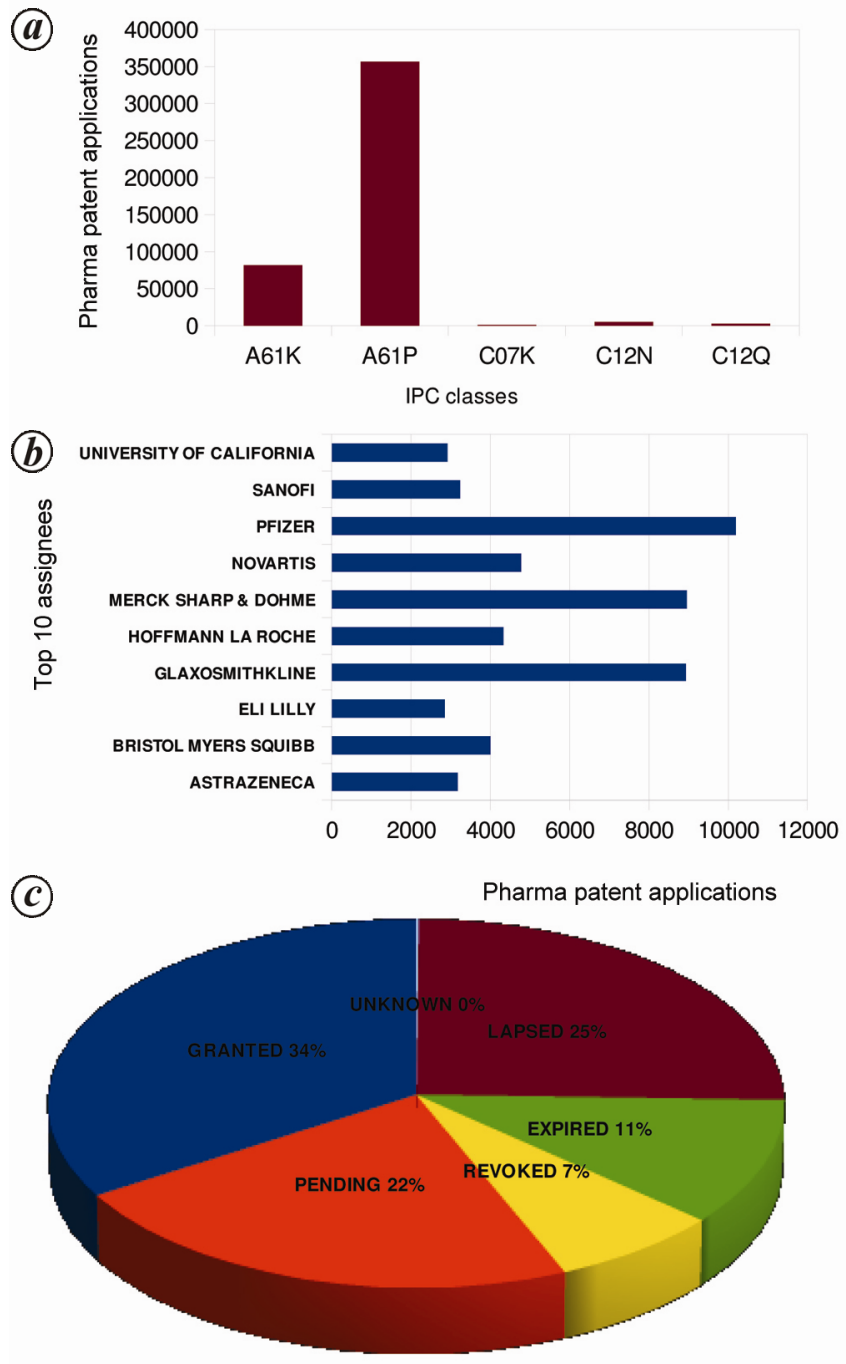

Figure 3. $\boldsymbol{a}$, Top five IPC classes of pharmaceutical patents. $\boldsymbol{b}$, Top ten global pharma patent assignees. $\boldsymbol{c}$, Legal status of pharma patent applications. 

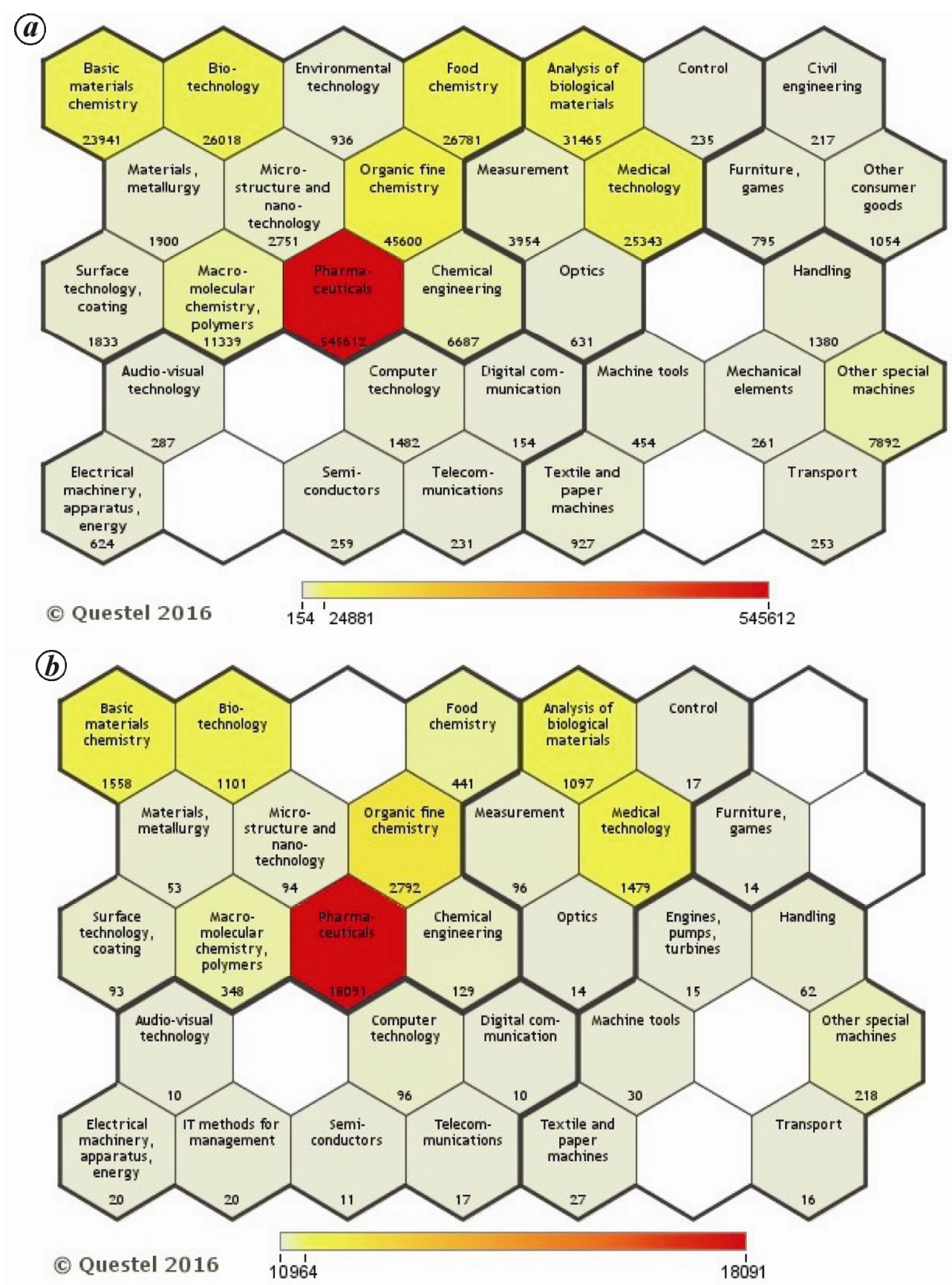

Figure 4. Technology domains: $\boldsymbol{a}$, Pharmaceuticals; $\boldsymbol{b}$, NSAIDs.

Globally, thyroid disorders - hypothyroidism and hyperthyroidism, influence about $5-10 \%$ of the population. The global market for treatment of thyroid gland disorders was 1.8 billion USD in 2014, and is predicted to reach 2.4 billion USD in 2023. The major companies in global thyroid gland disorder market are Abbott Laboratories, AbbVie, Mylan NV, Pfizer, GlaxoSmithKline, Merck KGaA, Novartis AG and Sanofi ${ }^{19}$. In India, hypothyroidism has an upper hand over hyperthyroidism, and is more prevalent among females $(66.4 \%)$ than males $(33.6 \%)^{20}$. The patents filed relating to hyperthyroidism drugs were lower in comparison with other lifestyle diseases considered in the present study. Fewer number of patents filed was observed in intermittent years, i.e. 2010, 2012 and 2014 (Figure 2 b).

\section{Questel - 'orbit' data findings}

Data on the top five IPC classes in pharma patent applications were analysed (Figure $3 a$ ). The majority of the pharmaceutical related patents was filed in Class A61P, i.e. specific therapeutic activity or chemical compounds for medical preparations, followed by class A61K, i.e. preparations for medical, dental or toilet purposes. The 

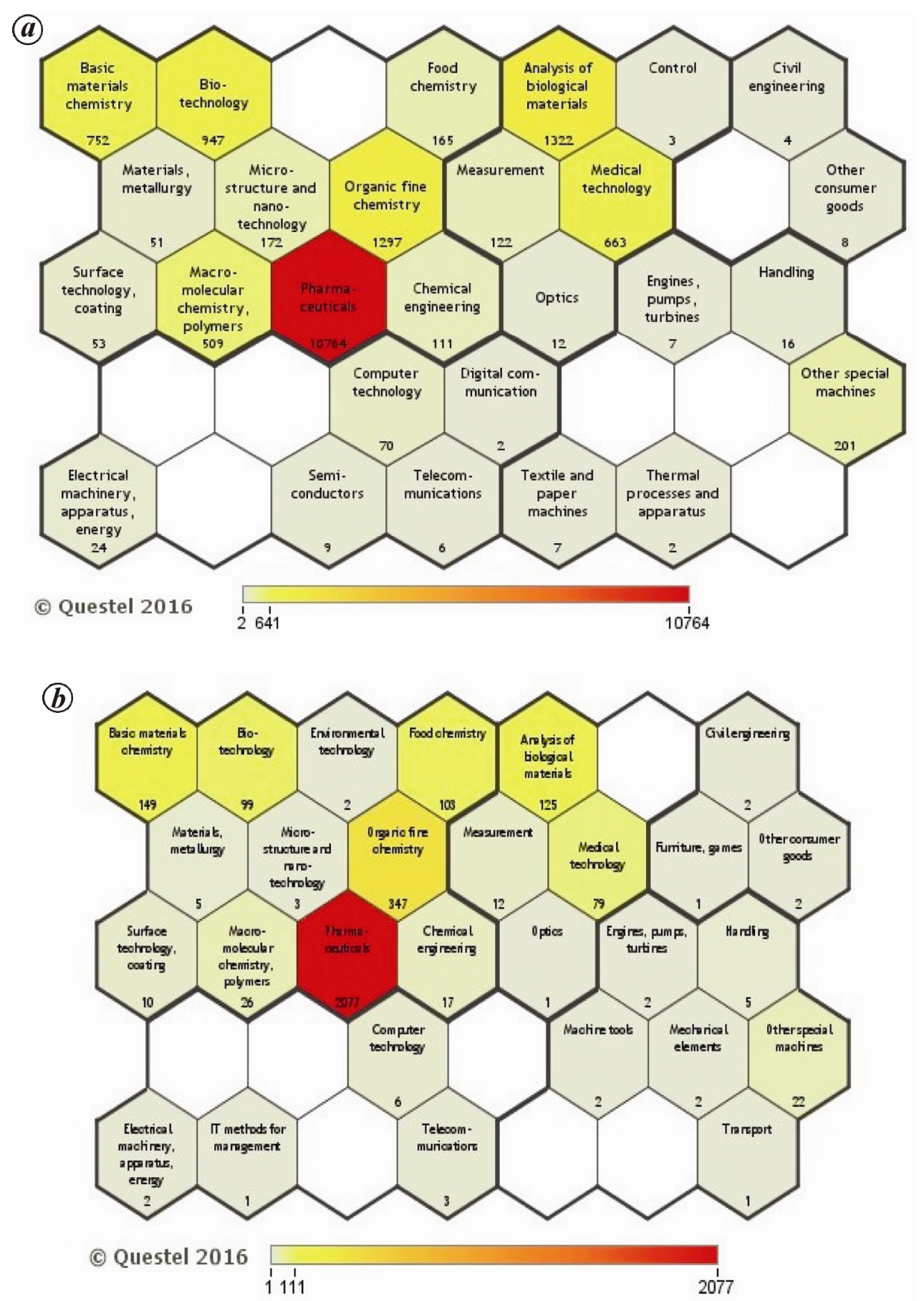

Figure 5. Technology domains: $\boldsymbol{a}$, anti-cancer drugs; $\boldsymbol{b}$, anti-diabetes drugs.

legal status of the pharma patent applications (Figure $3 b$ ) indicated that out of a total of $5,45,612$ pharma patent applications, 34\% have been granted, $25 \%$ lapsed without examination, $22 \%$ pending to be examained, $11 \%$ expired and $7 \%$ revoked. The top 10 pharma patent assignees were examined (Figure $3 c$ ); the three major assignees were Pfizer-10,191 applications, Merck Sharp and Dohme - 8955 and GlaxoSmithkline - 8938 .

Questel - 'Orbit' has categorized the patents under 35 technology domains based on IPC classes and subclasses.
The distribution of pharmaceutical patents and nonsteroidal anti-inflammatory drug (NSAIDs) patents under different technological domains was carried out. NSAIDs data were taken to characterize and analyse the patents correlating lifestyle diseases, because inflammation is the causal agent for majority of diseases, such as diabetes, cancer, arthritis, etc. The main technology domain having the maximum number of patents was 'pharmaceutical', which was depicted in red colour in the honeycomb graph (Figure $4 a$ and $b$ ). The other technological domains 


\section{RESEARCH ARTICLES}

under which a considerable number of patents categorized were (i) organic fine chemistry, (ii) analysis of biological materials, (iii) biotechnology, (iv) basic materials chemistry, (v) medical technology and (vi) food chemistry, and highlighted as yellow coloured cells in the figure. The empty cells in the figure represent the technology domains having no reports of patents related to pharmaceuticals and NSAIDs. The rapid growth of anti-cancer drugs and anti-diabetes drugs in the global market, has attained relevance as the two major lifestyle diseases affecting people. Reports of patents related to anti-cancer drugs and anti-diabetes drugs under various technology domains were analysed and illustrated in Figure $5 a$ and $b$ respectively.

\section{Concluding remarks}

The Indian health care system had a slow growth compared to global scenario. During the last two decades, the pharma patenting trends in India experienced a parabolic shift with lag phase, log phase and declining phase. Even though the pharma patenting has reduced, revenue from the pharma market has constantly increased making India one of the top 10 pharma markets globally. Marine pharmaceutical drugs have the potential for using cheaper input ingredients, which can replace the existing costly drugs. As ingredient prices come down, biosimilar drugs will become cheaper. This study emphasizes the importance of major investments in biosimilar drugs, particularly from the marine sector for emerging lifestyle diseases.

Conflict of interest declaration: The authors declare that they have no conflict of interest including any financial, personal or other relationships with other people or organizations that could inappropriately influence, or be perceived to influence the present work.

1. Global Pharmaceutical Market Outlook: 2015, Express Pharma, 2012; http://archivepharma.financialexpress.com/20120115/market02. $\underline{\text { shtml }}$

2. Arun, S., Government to hold talks with WIPO. The Hindu, 15 January 2016, p. 6.

3. Global pharma looks to India: Prospects for growth, PricewaterhouseCoopers, http://www.pwc.com/gx/en/pharma-life-sciences/pdf/ global-pharma-looks-to-india.pdf

4. Vidya, K. and Arun, S., India may cease to be "pharmacy of the world', The Hindu, 22 January 2016; http://www.thehindu.com/ todays-paper/tp-national/india-may-cease-to-be-pharmacy-of-theworld/article8136978.ece

5. Michael, M., WTO Reviews India's Trade Policies, Including Drug Patents, Compulsory Licensing, 2015; http://www.raps.org/ Regulatory-Focus/News/2015/06/03/22617/WTO-Reviews-IndiasTrade-Policies-Including-Drug-Patents-Compulsory-Licensing/

6. Unnikrishnan, C. H., Compulsory licences may spur more voluntary licensing deals; livemint, 2013; http://www.livemint.com/Home Page/f0R9060osU7bENFNwlnx5O/Compulsory-licences-may-spurmore-voluntary-licensing-deals.html
7. Sushmi, D., $25 \%$ of Indians may die of lifestyle diseases before they are 70, The Times of India, 13 August 2015; http://times ofindia.indiatimes.com/india/25-of-Indians-may-die-of-lifestylediseases-before-they-are-70-Study/articleshow/48460601.cms

8. Martin, P., Vikram, P., Shekhar, S., Mario, M., Joanna, M., Michael, R. P. and Atif, R., No health without mental health. The Lancet, 2007, 370(9590), 859-877.

9. Pharmaceutical Market India 2014-2020, Formulations, active pharmaceutical ingredients (APIs), contract research and manufacturing services (CRAMS), biosimilars, generics and vaccines, Kelly Scientific Publications, 2014, p. 13.

10. Matthew, H., The Cancer Drug Market Just Hit $\$ 100$ Billion and Could Jump 50\% In Four Years, Forbes, 2015; http://www. forbes.com/sites/matthewherper/2015/05/05/cancer-drug-sales-approach100-billion-and-could-increase-50-by-2018/\#7227004670f4

11. Asia Oncology Drug Market Outlook to 2019 - Driven by Rising Demand and Intensifying Joint Ventures between Companies, PRNewswire, 2015; http://www.prnewswire.com/news-releases/ asia-oncology-drug-market-outlook-to-2019---driven-by-risingdemand-and-intensifying-joint-ventures-between-companies300175417.html

12. Antidiabetics market analysis by product (Insulin, Biguanides, Thiazolodinediones, GLP-agonists, Sulphonylureas, DPP-4 inhibitors, SGLT-2, Alpha-glucosidase Inhibitors, Meglitinides) and segment forecasts to 2020, Grand View Research, 2015; http://www.grandviewresearch.com/industry-analysis/antidiabeticsmarket

13. Pharmaceuticals, Indian Brand Equity Foundation, 2016, p. 12; http://www.ibef.org/download/Pharmaceutical-January-2016.pdf

14. Rupali, M., Anti-diabetic drug tops India's pharma sales. The Times of India, 18 June 2014; http://timesofindia.indiatimes.com/ business/india-business/Anti-diabetic-drug-tops-Indias-pharma-sales/ articleshow/36731810.cms

15. Cadalmin antidiabetic extract-Cadalmin ${ }^{\mathrm{TM}} \mathrm{ADe}, C M F R I-$ eprints, 2015, http://eprints.cmfri.org.in/10483/1/Cadalmin_AD extract.pdf

16. Onkar, S. and Sufiyan, H., World anti-inflammatory therapeutics market - opportunities and forecasts, 2014-2020, Allied Market Research Report, 2015; https://www.alliedmarketresearch.com/ anti-inflammatory-therapeutics-market

17. Kajal, C., Intellectual property rights: a perspective in marine fisheries and mariculture, CMFRI Special Publication, 2013, 108, $72-73$.

18. Global Hypertension drugs market 2014-2018, Research and markets report, 2014; http://www.researchandmarkets.com/reports/ 2814392/global-hypertension-drugs-market-2014-2018

19. Thyroid gland disorders treatment market - global industry analysis, size, share, growth, trends and forecast 2015-2023, Transparency Market Research Press Release, 2015; http://www. transparencymarketresearch.com/thyroid-gland-disorder-market.html

20. Rajnish, N., Shirsendu, R., Mohammad, A., Vijay, P., Nayana, K. and Prakash, P., Incidence of thyroid disorders in India: an institutional retrospective analysis. Int. J. Dental Med. Speciality, 2015, 2(2), 19-23.

ACKNOWLEDGEMENTS. We thank Dr S. Mauria, ADG (IP\&TM), ICAR, New Delhi for guidance in this new subject area of IPR. We also thank ITMUs and ZTM\&BPD Unit of ICAR for providing timely information and encouragement to carry out this study. Financial support from Intellectual Technology Management Unit (ITMU) of the ICAR project and facilities provided by the Director, ICAR-CMFRI for the research work are acknowledged.

Received 25 May 2016; revised accepted 18 March 2017

doi: $10.18520 / \mathrm{cs} / \mathrm{v} 113 / \mathrm{i} 04 / 725-732$ 


\section{CURRENT SGENCE}

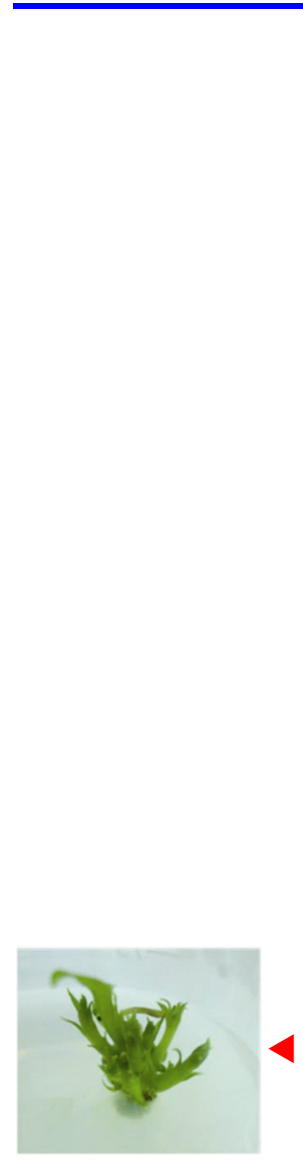

532

In this issue

GUEST EDITORIAL

533 Of launches and lunches

R. Uma Shaanker

\section{CORRESPONDENCE}

535 An IISc-Tsinghua head-to-head evaluation of research using CWTS Leiden Ranking 2017 data, Gangan Prathap 537 Basic science and 'Make in India', B. A. Dasannacharya 537 Fungal endophytes: nature's tool for bioremediation of toxic pollutants, B. Shankar Naik

\section{NEWS}

540 Science Last Fortnight $\square 544$ Scientific Video Publication? By JoVE!, K. P. Madhu 546 Technology, youth and career: a paradigm shift, Sangeeta Kakoty, Yamin Hassan and B. G. Unni 547 Indian Academy of Sciences, Bengaluru - 28th Mid-Year Meeting, Sushila Rajagopal, Geetha Sugumaran, Savitha Sekhar and S. Priya

\section{COMMENTARY}

550 Danger of a single score: NIRF rankings of colleges Gangan Prathap

\section{OPINION}

553 Polarity, asymmetry and aging: are there Yayatis among bacteria? Ulfat Baig, Milind Watve and Uttara Lele

\section{SCIENTIFIC CORRESPONDENCE}

555 Micropropagation of Symplocos racemosa Roxb., a threatened medicinal tree of India, Shashikanta Behera, Durga P. Barik and Soumendra K. Naik $\square 558$ Antibacterial activity of some important medicinal plants, Vinod K. Bisht, Bir S. Negi, Arvind K. Bhandari, Rakesh S. Bisht and Jagdish C. Kaim $\square 561$ Bioacoustics or pitfall traps: comparison of a modern and traditional method to estimate Ensifera richness, Manisha Tomar, Abhay Pratap Singh and Swati Diwakar

\section{GENERAL ARTICLES}

564 Print mass media coverage of wildlife in the developing world Salvador Lyngdoh, Divya Dixit and Bitapi C. Sinha

571 Bioprospecting of medicinal plants in Nanda Devi Biosphere Reserve: Linking conservation with livelihood

R. K. Maikhuri, Vikram S. Negi, L. S. Rawat and D. S. Pharswan

\section{SPECIAL SECTION: ASTRONOMY}

578 Preface

Ajit Kembhavi

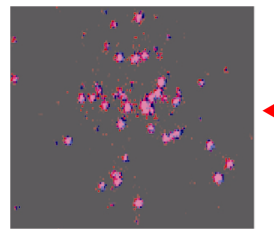

579 Overview of the AstroSat mission

S. Seetha and S. Megala

583 Ultraviolet Imaging Telescope on AstroSat

S. N. Tandon, S. K. Ghosh, J. Hutchings, C. S. Stalin and A. Subramaniam 
587 Soft X-ray focusing Telescope aboard AstroSat: early results

K. P. Singh, G. C. Dewangan, S. Chandra, S. Bhattacharayya, V. Chitnis, G. C. Stewart and N. J. Westergaard

591 Large Area X-ray Proportional Counter instrument on AstroSat

J. S. Yadav, P. C. Agrawal, H. M. Antia, R. K. Manchanda, B. Paul and Ranjeev Misra

595 Cadmium-Zinc-Telluride Imager on-board AstroSat: a multi-faceted hard X-ray instrument

A. R. Rao, D. Bhattacharya, V. B. Bhalerao, S. V. Vadawale and S. Sreekumar

599 Scanning Sky Monitor on-board AstroSat

M. C. Ramadevi, S. Seetha, Dipankar Bhattacharya, B. T. Ravishankar, N. Sitaramamurthy, G. Meena, M. Ramakrishna Sharma, Ravi Kulkarni, V. Chandra Babu, Kumar, Brajpal Singh, Anand Jain, Reena Yadav, S. Vaishali, B. N. Ashoka, Anil Agarwal, K. Balaji, Manoj Kumar, Prashanth Kulshresta, Pankaj Agarwal and Mathew Sebastian

602 Multi-colour hues of the Universe observed with AstroSat

K. P. Singh and D. Bhattacharya

610 Aditya-L1 mission

S. Seetha and S. Megala

613 Visible Emission Line Coronagraph on Aditya-L1

B. Raghavendra Prasad, Dipankar Banerjee, Jagdev Singh, S. Nagabhushana, Amit Kumar, P. U. Kamath, S. Kathiravan, Suresh Venkata, N. Rajkumar, V. Natarajan, Madhur Juneja, Pawan Somu, Vaibhav Pant, Nigar Shaji, K. Sankarsubramanian, Asit Patra, R. Venkateswaran, Abhijit Avinash Adoni, S. Narendra, T. R. Haridas, Shibu K. Mathew, R. Mohan Krishna, K. Amareswari and Bhavesh Jaiswal

616 The Solar Ultraviolet Imaging Telescope on-board Aditya-L1

Durgesh Tripathi, A. N. Ramaprakash, Aafaque Khan, Avyarthana Ghosh, Subhamoy Chatterjee, Dipankar Banerjee, Pravin Chordia, Achim Gandorfer, Natalie Krivova, Dibyendu Nandy, Chaitanya Rajarshi and Sami K. Solanki

620 Probing the heliosphere using in situ payloads on-board Aditya-L1

P. Janardhan, Santosh Vadawale, Bhas Bapat, K. P. Subramanian, D. Chakrabarty, Prashant Kumar, Aveek Sarkar, Nandita Srivastava, R. Satheesh Thampi, Vipin K. Yadav, M. B. Dhanya, Govind G. Nampoothiri, J. K. Abhishek, Anil Bhardwaj and K. Subhalakshmi

625 X-ray spectrometers on-board Aditya-L1 for solar flare studies

K. Sankarasubramanian, Manju Sudhakar, Anuj Nandi, M. C. Ramadevi, Abhijit Avinash Adoni, Ankur Kushwaha, Anil Agarwal, Arjun Dey, Bhuwan Joshi, Brajpal Singh, V. Girish, Ishan Tomar, Kamal Kumar Majhi, Kumar, Manjunath Olekar, Monoj Bug, Manohar Pala, Mukund Kumar Thakur, Rajeev R. Badagandi, B. T. Ravishankar, Sarthak Garg, N. Sitaramamurthy, N. Sridhara, C. N. Umapathy, Vinod Kumar Gupta, Vivek Kumar Agrawal and B. Yougandar

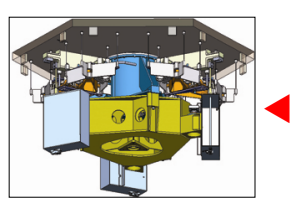

628 Development of the Thirty-Meter Telescope project Edward Stone and Michael Bolte

631 India's participation in the Thirty Meter Telescope International Observatory project B. Eswar Reddy and A. N. Ramaprakash

639 The Thirty Meter Telescope International Observatory facilitating transformative astrophysical science

Warren Skidmore, G. C. Anupama and Raghunathan Srianand

649 India and the Square Kilometre Array

Philip Diamond and Yashwant Gupta

657 The first direct detection of gravitational waves opens a vast new frontier in astronomy F. J. Raab and D. H. Reitze

663 Cosmic sirens: discovery of gravitational waves and their impact on astrophysics and fundamental physics

Sanjeev Dhurandhar and Bangalore S. Sathyaprakash 
672 LIGO-India - a unique adventure in Indian science

Tarun Souradeep, Sendhil Raja, Ziauddin Khan, C. S. Unnikrishnan and Bala Iyer

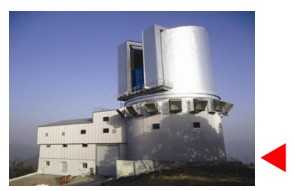

Multi-messenger astronomy

Varun Bhalerao

682 Scientific capabilities and advantages of the 3.6 meter optical telescope at Devasthal, Uttarakhand

Amitesh Omar, Brijesh Kumar, Maheswar Gopinathan and Ram Sagar

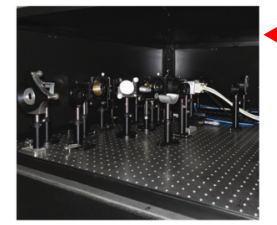

686 The Multi Application Solar Telescope

P. Venkatakrishnan, Shibu K. Mathew, Nandita Srivastava, A. R. Bayanna, Brajesh Kumar, Bireddy Ramya, Naresh Jain and Mukesh Saradava

691 MACE gamma-ray telescope - a status update

Ramesh Koul

696 National Large Solar Telescope

S. S. Hasan, D. Banerjee, B. Ravindra, K. Sankarasubramanian and K. E. Rangarajan

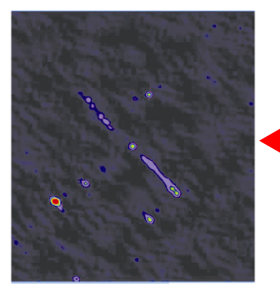

701 India-based Neutrino Observatory

Vivek M. Datar and Naba K. Mondal

707 The upgraded GMRT: opening new windows on the radio Universe

Y. Gupta, B. Ajithkumar, H. S. Kale, S. Nayak, S. Sabhapathy, S. Sureshkumar, R. V. Swami, J. N. Chengalur, S. K. Ghosh, C. H. Ishwara-Chandra, B. C. Joshi, N. Kanekar, D. V. Lal and S. Roy

\section{REVIEW ARTICLE}

715 PGPR-assisted phytoremediation of cadmium: an advancement towards clean environment Chhaya Verma, Amar Jyoti Das and Rajesh Kumar

RESEARCH ARTICLES

725 Pharmaceutical patenting trends on drugs and lifestyle diseases: an analysis of Indian and global status

Vikram Singh, Kajal Chakraborty and Lavina Vincent

733 Understanding relationship between melt/freeze conditions derived from spaceborne scatterometer and field observations at Larsemann Hills, East Antarctica during austral summer 2015-16

Rajashree V. Bothale, S. Anoop, V. V. Rao, V. K. Dadhwal and Y. V. N. Krishnamurthy

743 Channel morphology and hydraulic geometry of River Kolong, Nagaon district, Assam, India: a study from the standpoint of river restoration Minakshi Bora and Dulal C. Goswami

752 Dry biomass partitioning of growth and development in wheat (Triticum aestivum $\mathbf{L}$.) crop using CERES-wheat in different agro climatic zones of India

P. K. Singh, K. K. Singh, K. K. Gill, Ram Niwas, R. S. Singh and Sanjay Sharma

767 Screening of autochthonous intestinal microbiota as candidate probiotics isolated from four freshwater teleosts

Ankita Nandi, Goutam Banerjee, Suhas Kumar Dan, Pinki Ghosh, Koushik Ghosh and Arun Kumar Ray

\section{RESEARCH COMMUNICATIONS}

774 Offshore wind to meet increasing energy demands in India

Satya Kiran Raju Alluri, Trishanu Shit, G. Dhinesh, Devender Gujjula, S. V. S. Phani Kumar and M. V. Ramana Murthy

782 Quantification of carbon stocks and sequestration potential through existing agroforestry systems in the hilly Kupwara district of Kashmir valley in India

Ajit, A. K. Handa, S. K. Dhyani, G. M. Bhat, A. R. Malik, V. Dutt, T. H. Masoodi, Uma and Amit Jain

785 Fusion of ginseng farnesyl diphosphate synthase and Centella asciatica squalene synthase involved in triterpenoid biosynthesis

Su Jin Jung, Young Chang Kim, Mei Lan Jin, Reinhard Jetter and Ok Tae Kim 
790 Optimization of key factors for enhanced fermentative biohydrogen production from water hyacinth by RSM

Veena Thakur, Mona Tandon and S. K. Jadhav

795 Ionospheric precursors observed in TEC due to earthquake of Tamenglong on 3 January 2016

Sanjay Kumar and A. K. Singh

\section{BOOK REVIEWS}

802 Innovative Approaches in Drug Discovery: Ethnopharmacology, Systems Biology and Holistic Targeting, Bhushan Patwardhan and Rathnam Chaguturu, reviewed by $\mathrm{S}$. Chandrasekhar

803 The Planet Remade: How Geoengineering Could Change the World by Oliver Morton, reviewed by Sudhirendar Sharma

PERSONAL NEWS

804 Yash Pal (1926-2017)

R. Cowsik

807 Pushpa Mittra Bhargava (1928-2017)

Durgadas P. Kasbekar

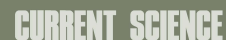

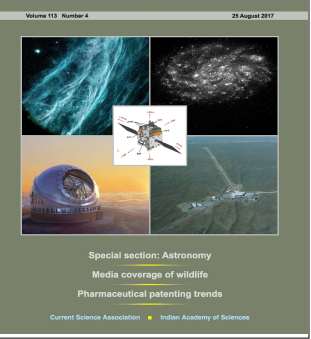

COVER. Top panel left: UVIT 3 colour composite image of the 'witches broom' nebula (NGC 6960) in the Cygnus loop, covering wavelength range 1380-1780 (Sutaria, F. K. et al.); Top panel right: UVIT Far-Ultraviolet image of the spiral galaxy NGC 300 by the UVIT Team; Bottom panel left: An impression of the Thirty Meter Telescope (courtesy TMT-National Astronomical Observatory of Japan); Bottom panel right: The LIGO installation near Hanford, Washington State (courtesy Caltech/ MIT/LIGO Lab) - LIGO-India will be very similar to this. Centre: A rendering of AstroSat. See special section.

The editor thanks Ajit Kembhavi, Inter-University Centre for Astronomy \& Astrophysics, Pune for agreeing to be guest editor for the special section.

Indexed in CURRENT CONTENTS/GEOBASE/CHEMICAL ABSTRACTS/IndMED/SCOPUS/ WEB OF SCIENCE 